\title{
Integrated Model for Kimberlite Ascent and Eruption
}

\author{
James W. Head III ${ }^{\mathbf{1}}$ and Lionel Wilson ${ }^{\mathbf{1}, 2}$ \\ ${ }^{I}$ Dept. of Geological Sciences, Brown University, Providence, R.I. 02912, U.S.A., \\ ${ }^{2}$ Environmental Science Dept., Lancaster University, Lancaster, U.K.
}

Class 1 kimberlite deposits (Field and Scott Smith, 1999; Skinner and Marsh, 2004), and the diatremes with which they are associated, are characterized by many unusual and enigmatic morphological properties. We have argued that may of these properties can be understood as the consequences of transient events that take place during the opening of a pathway from a deep mantle magma source to the surface (Wilson and Head, 2007). Even if subsequent events modify the initial structures after the transient opening to the surface, especially if a prolonged eruption occurs (Sparks et al., 2006), such changes are unlikely to completely destroy the initially imposed morphology. The event is initiated with the formation of a brittle fracture at unusually great depth in the mantle. Once this process is initiated, it is self-sustaining. Our model focuses on the pressure distribution in a dike throughout its ascent as its upper tip propagates to the surface, and the aftermath once the pressurized volatile fluid vents to the atmosphere and a dramatic pressure decrease occurs in the shallow part of the dike.
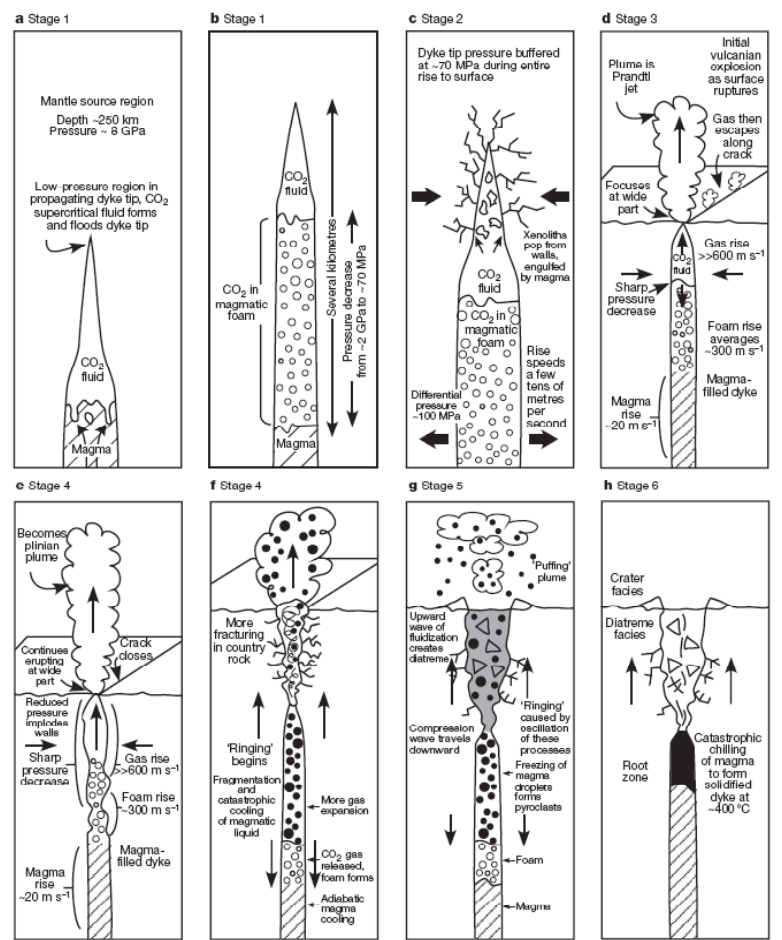

Fig. 1. Sequence in the generation, ascent and eruption of kimberlite magmas and diatreme formaton (Wilson and Head, 2007a).
Here, and elsewhere, we describe the main phases (Fig. 1) of the ascent, eruption, and diatreme formation (Wilson and Head, 2007a,b, 2008; see also Sparks et al., 2006, 2007) emphasizing the extremely unsteady nature of the eruption process.

Stage 1. Dike tip propagation from the deep source region and $\mathrm{CO}_{2}$ fluid segregation. The dike sets out from the mantle source at a depth of $\sim 250 \mathrm{~km}$, where the pressure is $\sim 8 \mathrm{GPa}$ (Fig. 1a). Magma in the dike could contain as much as 20 weight $\% \mathrm{CO}_{2}$, and the pressure-dependent solubility of this volatile is such that the dike tip pressure, in attempting to reach the lowest possible value in order to maximize the magma flow speed, would initially be buffered at $\sim 2 \mathrm{GPa}$ with release of $90 \%$ of the available $\mathrm{CO}_{2}$ as a supercritical fluid filling the cavity behind the dike tip. A foam layer rapidly develops beneath the tip cavity due to the difficulty of diffusing the volatile phase into the cavity (Fig. 1b). Fluid bubbles in the foam burst into the cavity, causing decreases in cavity pressure (Wilson and Head, 2003) to the value at which the bubble volume fraction is $\sim 0.7-0.8$, the condition under which volcanic foams commonly disintegrate into a continuous volatile phase containing entrained droplets of the magmatic liquid. The $\mathrm{CO}_{2}$ density at which $\sim 20$ weight $\%$ forms bubbles occupying $\sim 75 \%$ of the volume at magmatic temperatures is $\sim 220 \mathrm{~kg} \mathrm{~m}^{-3}$. Using thermodynamic data for supercritical $\mathrm{CO}_{2}$, this corresponds to a pressure of $\sim 70 \mathrm{MPa}$. Thus, the pressure decreases upward from $\sim 2 \mathrm{GPa}$ to $\sim 70 \mathrm{MPa}$ across the foam layer. The supply of $\mathrm{CO}_{2}$ is constantly renewed by streaming of degassed magma to the sides of the dike as the dike grows both upward and laterally, exposing fresh undegassed magma in the dike center. The tip cavity grows in length in a manner controlled by the elastic stresses acting over the upper part of the dike; it may be $2-4 \mathrm{~km}$ long by the time the dike tip is near the surface.

Stage 2: Dike ascent and wall fracturing. As magma ascends from the source region at a pressure of $\sim 8 \mathrm{GPa}$ to the base of the foam layer at $\sim 2 \mathrm{GPa}$ it will cool adiabatically from $\sim 1650 \mathrm{~K}$ to $\sim 1450 \mathrm{~K}$. Its passage through the foam layer from a pressure of $\sim 2 \mathrm{GPa}$ to $\sim 70 \mathrm{MPa}$ can be treated as the adiabatic expansion of a pseudo-gas, resulting in cooling from $\sim 1450 \mathrm{~K}$ to $\sim 1110 \mathrm{~K}$. The pressure difference in excess of the static weight of the magma column (source pressure minus tip pressure) will be fixed at $\sim 8 \mathrm{GPa}$, and on 
subtracting the static weight of the magma column the pressure difference driving the magma motion vaies from $\sim 8 \mathrm{GPa}$ at great depth to $\sim 1 \mathrm{GPa}$ near the surface. Dividing by the length of the magma column yields a pressure gradient ranging from $\sim 1 \mathrm{MPa} \mathrm{m}^{-1}$ at great depth to $\sim 4 \mathrm{kPa} \mathrm{m}^{-1}$ near the surface. The average pressure gradient of more than $60 \mathrm{kPa} \mathrm{m}^{-1}$ is $\sim 20$ times larger than the gradients driving basaltic eruptions from shallow magma reservoirs and leads to the magma flowing upward in a turbulent manner with an average rise speed of $\sim 30-50 \mathrm{~m} / \mathrm{s}$, implying an extremely short transit time (Fig. 1c).

The dike tip pressure is buffered at $\sim 70 \mathrm{MPa}$ during the entire rise to the surface but the external pressure decreases due to decreasing overburden. Wall rocks adjacent to the propagating dike tip region are fractured in tension over most of the rise distance of the dike (Fig. 1c). Country rock is torn from the walls to become xenoliths; it quickly sinks through the $\mathrm{CO}_{2}$ fluid to become engulfed by and incorporated into the underlying magmatic foam. Over the last several $\mathrm{km}$ of magma rise, the stress across the dike walls changes from tensile to compressive, with the possibility of intrusion of small dikelets due to the decreasing overburden pressure. The relative abundance of xenoliths produced by wall rock fracturing will be a function of rock strength and position in the crust relative to the evolving differential stress; the most important factor will be the elapsed time for which the wall rocks are exposed to dike emplacement, favoring deep xenoliths.

Stage 3: Dike tip breaks surface, vents $\mathrm{CO}_{2}$ gas, implodes walls. The propagating dike is convex upward along its length and first reaches the surface at its highest central point, immediately starting to vent the $\mathrm{CO}_{2}$ fluid in the dike tip cavity (Fig. 1d). Upon being exposed to the surface, the supercritical fluid expands adiabatically to atmospheric pressure to become a subcritical gas, producing an initial vulcanian explosion. Its upward velocity increases from the $\sim 20$ $\mathrm{m} / \mathrm{s}$ rise speed of the dike to a speed which depends on the amount of clastic material which it carries. If a pure gas is released its speed will be $\sim 1.4 \mathrm{~km} \mathrm{~s}^{-1}$ and it will have cooled adiabatically to $\sim 300 \mathrm{~K}$. If the gas is loaded with all of the magma in the form of small droplets its speed will be $\sim 600 \mathrm{~m} \mathrm{~s}^{-1}$ and its temperature $\sim 680 \mathrm{~K}$, and if it is loaded by magma droplets and an equal mass of host rock wall fragments the values will be $\sim 300 \mathrm{~m} \mathrm{~s}^{-1}$ and $\sim 500 \mathrm{~K}$. The expansion wave causing this violent acceleration of the cavity fluid will propagate downward through it at about half the speed of sound in $\mathrm{CO}_{2}$ at magmatic temperature, i.e. $\sim 300 \mathrm{~m} \mathrm{~s}^{-1}$, emptying a typically $3 \mathrm{~km}$ deep cavity in $\sim 10$ seconds. The mixture of gas and entrained particles ejected into the atmosphere will produce a classic Prandtl jet that will begin to interact with the surrounding air to produce a plinian or subplinian eruption plume (Fig. 1e). The dike will rapidly centralize along the widest portion (almost certainly the central part that reaches the surface first and within which the rise speed of magma and gas is greatest) and the remainder of the upper part of the gas-filled dike will rapidly close. This produces a linear fractured and crushed zone with little to no evidence of associated magma, in the center of which is a much more equant central vent. Within this vent, the break-through and the ensuing gas jet will rip wall rock from the uppermost country rock, and the proportion of shallow country rock should be high in the initial ejecta deposits around the vent. Simultaneously, the sharp decrease in pressure, caused by the gas venting, fractures and implodes the walls of the upper part of the dike.

Stage 4: Depressurization wave propagates into magmatic foam and underlying magma. The depressurization wave initiated by the gas venting next propagates down through the layer of magmatic foam at about half the speed of sound in the foam, i.e. $\sim 50 \mathrm{~m}$ $\mathrm{s}^{-1}$, expanding the bubbles and disrupting the foam into magma droplets and released gas (Fig. 1e). The wave continues into the underlying magma at about half the speed of sound in the bubble-free liquid, (i.e., $\sim 800 \mathrm{~m}$ $\mathrm{s}^{-1}$ ), and more $\mathrm{CO}_{2}$ is released in the magma-filled portion of the dike, forming additional foam which also expands and is disrupted (Fig. 2F). In both cases the assemblage of gas and entrained magma droplets will cool from $\sim 1110 \mathrm{~K}$ to $\sim 680 \mathrm{~K}$ as long as the front of the expansion wave is maintained at atmospheric pressure. During the disruption and expansion process (Fig. 1f), surface tension will form the resulting liquid fragments into spheres to optimize surface area to volume. These spheres would incorporate any solid particles in the rising magma (olivine phenocrysts, xenolithic grains) which had acted as nuclei for the volatile bubbles, and the very rapid adiabatic cooling of these particles would produce glassy or microcrystalline spherules, cored by phenocrysts and xenoliths, the pelletal lapilli of the TKB. Cooling would be so rapid (going from magmatic to room temperature in seconds) that welding of particles and agglutinization would be minimized.

\footnotetext{
Stage 5: Gas expansion creates upward fluidization wave, accelerates chilled pyroclasts. The gas expansion in the dike caused by the gas venting accelerates the gas into the shattered country rock and produces an upward wave of fluidization that is the major cause of the formation of the diatreme structure (Fig. 1g). The combination of foam disintegration in the upper part of the dike below the continuous gas phase, and the further foam formation and disintegration in the magma below the initial magmatic foam zone, is responsible for the upward fluidization wave. This produces a cold stream of gas through the upper part of the zone, which contains cooled spherules and fine-grained magmatic particles that migrate through the upper fractured zone and vent to the surface (Fig. 1f). Very quickly, however, partial clogging of the pathways and increasing path length cause a growing pressure gradient to be developed in
} 
the upper part of the system, and the information that this is occurring propagates downward as a wave of compression (Fig. 1g). Variations in pressure will cause instabilities in the gas exsolution process and gas flow speed and this will introduce cyclic waves of gas release, pressure changes and venting. A series of fluidization waves (a 'ringing') will propagate through the system. Given the low speed of sound in the complex gas/clast/bubbly liquid mixture, this may last for several tens of minutes. During this time, continual readjustments in the diatreme will be taking place as compression and decompression waves propagate back and forth, and a flow of cool gas transporting particles will permeate the diatreme zone and vent to the surface. This fluidization will cause sorting in the brecciated diatreme zone and will allow settling of large blocks of the country rock from the upper part of the column down into deeper parts of the diatreme. The disruption phase will also serve to modify, distort and destroy evidence of earlier stages of dike emplacement. During this time, the magma deeper in the dike itself will quickly undergo catastrophic adiabatic chilling (Fig. 1h) and thus will cease to rise into the diatreme. The deposits on the surface should be characterized by a basal coarse breccia from the initial venting, followed by coarse fragments, xenoliths and lapilli from the initial magmatic foam phase, followed by deposits dominated by products from the second magmatic foam phase (chilled lapilli and ash). The extreme cooling of the magma will inhibit its rise into the vent and any subsequent eruption of surface flows. Diamonds are emplaced into the diatreme facies as part of the kimberlite magma from below the gas and foam zones, where the melt stays at high pressure.

Stage 6: Event Aftermath. Following the event, the deposits will be characterized by a porous, cone-shaped diatreme surrounded by a crater rim of breccia and pyroclastic deposits. If the diatreme forms in an active groundwater area, a crater lake is likely to form and groundwater will permeate the diatreme, quickly altering the primary mineralogy. Although the predicted surface deposits are similar in some ways to those of tuff cones and maars formed by hydrovolcanic processes, no part of this model requires interaction of the rising dike with groundwater. Such an interaction could happen, but the very rapid chilling of the magmatic foams minimizes the likelihood of prolonged and repetitive hydrovolcanic eruptions occurring during the formation of diatremes.

This model accounts for the major observational characteristics of Class 1 kimberlites associated with diatremes. The termination of the eruption immediately after diatreme formation is a direct consequence of the extreme cooling of magma during the large pressure reductions that occur upon venting to the atmosphere. The subsequent very rapid pressure and temperature fluctuations lead to the formation of a diverse suite of rock types in the intrusive deposits. Only limited amounts of pyroclastic materials are expected to be erupted onto the surface. No precursor to the eruption is felt at the surface and the processes can be completed in a minimum of several hours. Cases in which abundant $\mathrm{CO}_{2}$ was lacking in deep melt sources and water was the dominant mantle volatile could result in kimberlite dike intrusions and eruptions without diatreme formation. Such events could be of a more protracted nature, building up extensive surface deposits similar to those of traditional basaltic pyroclastic eruptions (Sparks et al., 2006; Wilson and Head, 2008).

\section{References}

Field, M., Scott Smith, B. 1999. Contrasting Geology and Near-Surface Emplacement of Kimberlite Pipes in Southern Africa and Canada. Proc. $7^{\text {th }}$ Int. Kimberlite Conf. 1, 214-237, J. Gurney, Ed. (Cape Town).

Head, J. W., Wilson, L., 2008. Integrated model for kimberlite ascent and eruption, 9th International Kimberlite Conference Extended Abstract No. 9IKC-A-00284.

Lister, J. R., 1990. Buoyancy-driven fluid fracture: The effects of material toughness and of low-viscosity precursors. Journal of Fluid Mechanics, 210, 263280.

Rubin, A. M., 1993. Dikes vs. diapirs in viscoelastic rock. Earth Planet. Sci. Lett., 119, 641-659.

Sim, B.L., Agterberg, F.P., 2006. A conceptual model for kimberlite emplacement by solitary interfacial megawaves on the core mantle boundary. Journal of Geodynamics, 41, 451-461.

Skinner, E., Marsh, J., 2004. Distinct kimberlite pipe classes with contrasting eruption processes. Lithos, 76, 183200.

Sparks, R.S.J., Baker, L., Brown, R.J., Field, M., Schumacher, J., Stripp, G., Walters, A., 2006. Dynamical constraints on kimberlite volcanism. Journal of Volcanology and Geothermal Research, 155, 18-48.

Sparks, R.S.J., Brown, R.J., Field, M., Gilbertson, M., 2007. Kimberlite ascent and eruption. Nature 450, doi:10.1038/nature06435.

Wilson, L., Head, J. W., 2003. Deep generation of magmatic gas on the Moon and implications for pyroclastic eruptions, Geophysical Research Letters 30. (12), 1605, doi: 10.1029/2002GL016082.

Wilson, L., Head, J.W., 2007a. An integrated model of kimberlite ascent and eruption. Nature 447, (7140), 5357, doi:10.1038/nature05692.

Wilson, L., Head, J.W., 2007b. Kimberlite ascent and eruption. Nature 450, doi:10.1038/nature06436.

Wilson, L., Head, J. W., 2008. Dynamic consequences of the emplacement of kimberlite dikes. 9th International Kimberlite Conference Extended Abstract No. 9IKCA-00285. 